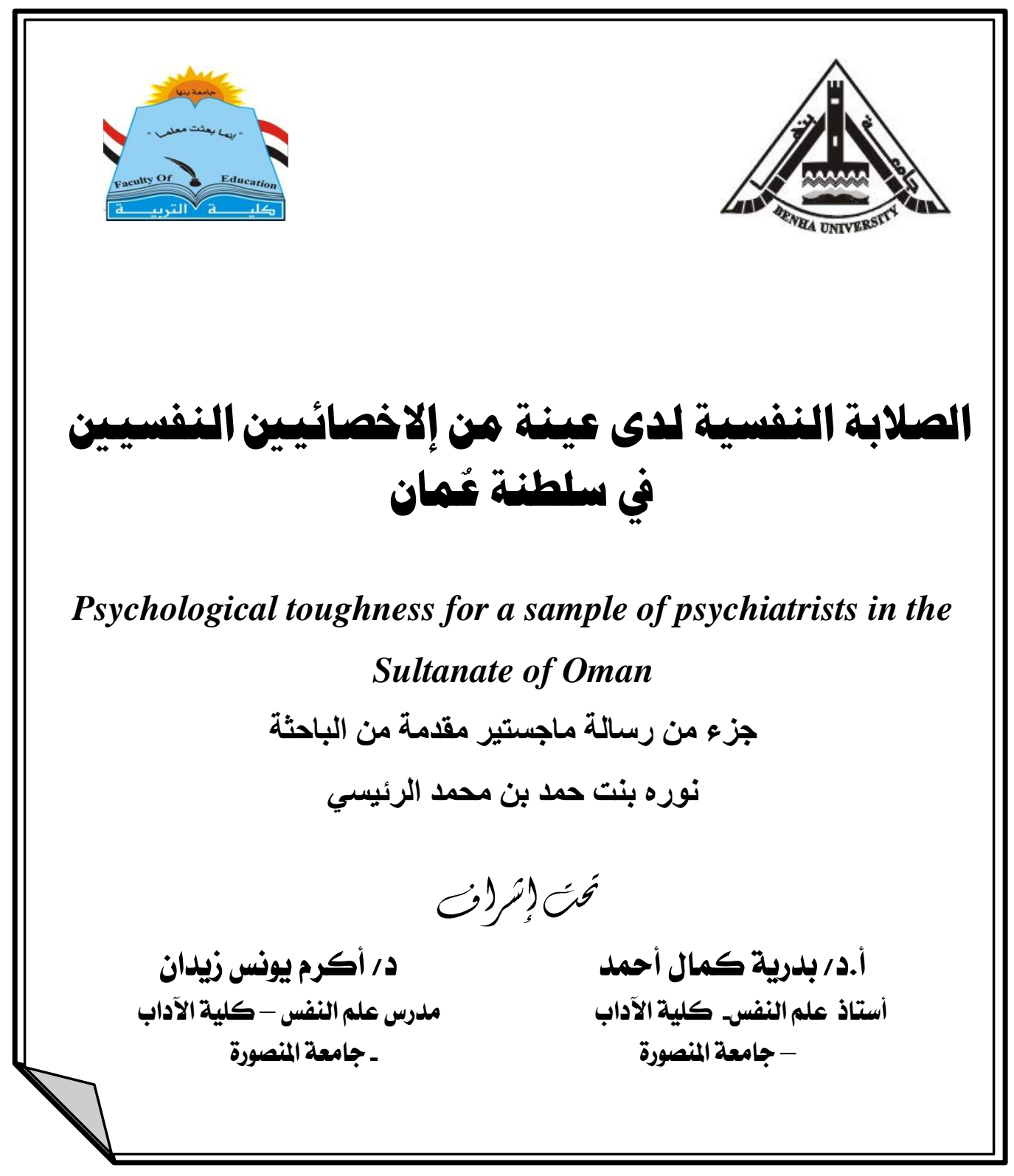




\section{الصلابة النفسية لدى عينة من إلاخصائيين النفسيين في سلطنة عُمان}

\section{Psychological toughness for a sample of psychiatrists in the Sultanate of Oman} جزء من رسالة ماجستير مقدمة من الباحثة

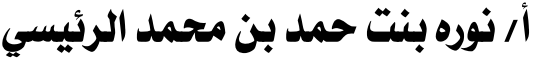

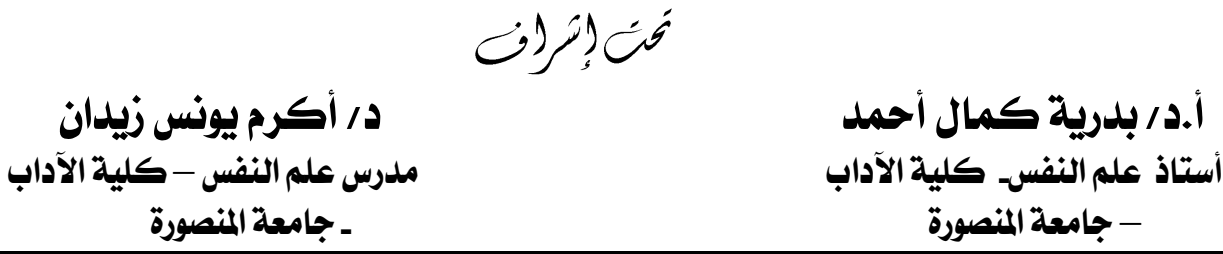

\section{هلذص البمث}

تهدف هذه الدراسة إلى التعرف على الصلابة النفسية لاى عينة من الأخصائيين

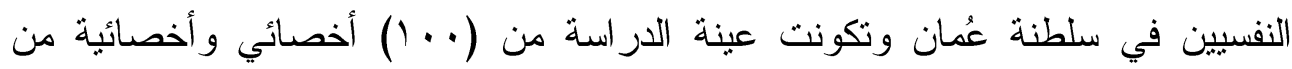

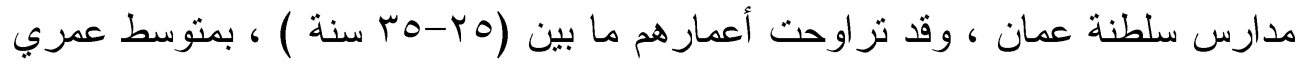

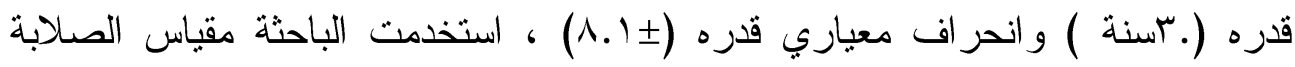

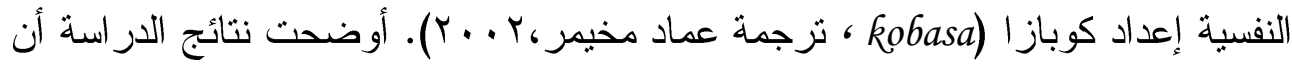

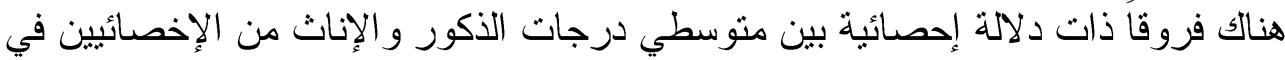

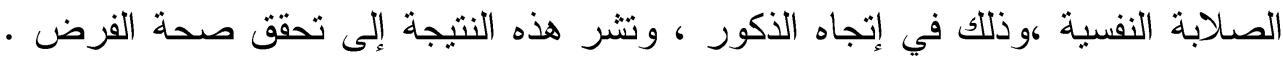

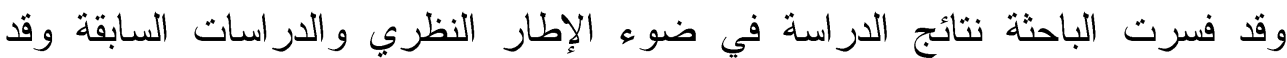
خرجت الباحثة ببعض التوصيات و البحوث المقترحة .

المقدهة:

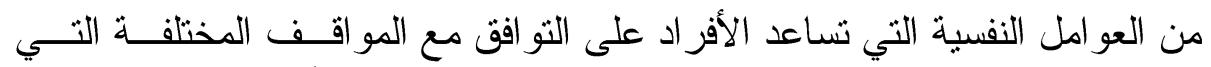

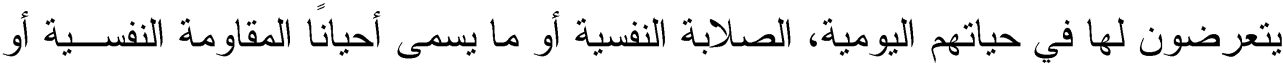

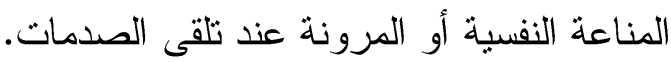
وتتمثل أبعاد الصلابة النفسية في "الالتز ام" وهو نوع من التعاقد النفسي يلتزم به الفرد تجاه

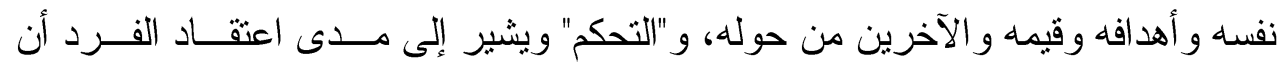

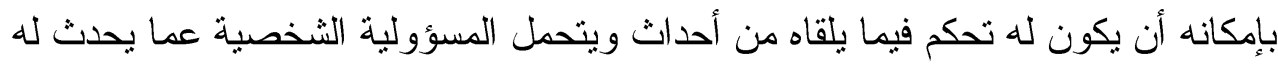

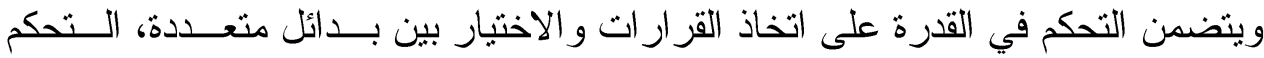

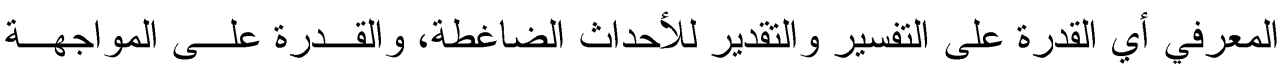

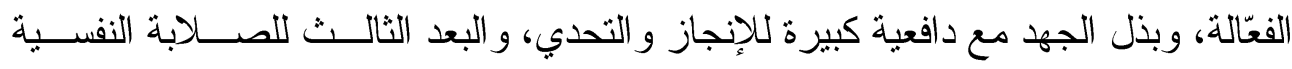


"التحدي" وهو اعتقاد الشخص أن ما يطر أ من تغيير على جو انب حياته هو أمــره" مثـــر"

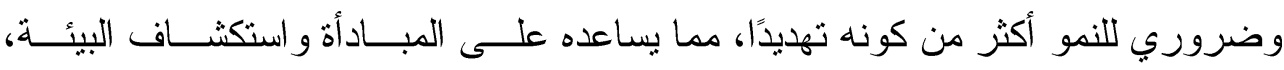

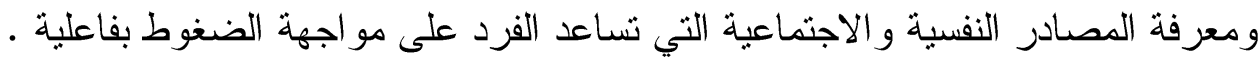

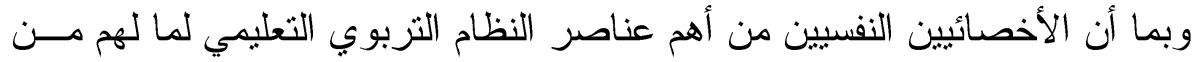

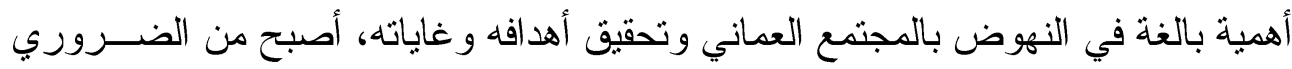

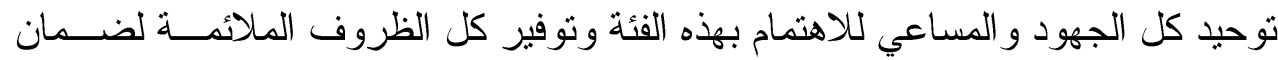

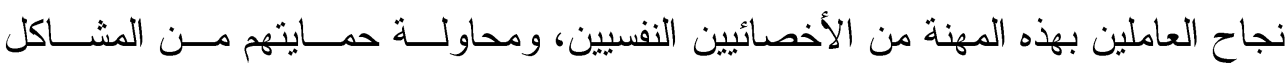
و الضغوطات التي قد تو اجهر خلال ذلك، و التي قد تتعكس سلبًا على أدائهم الوظيفي، وقد تكون حاجزًا و عائقاً كبيرًا أمام الكثيرين تمنعهم حتى من مو اصلة عملهم بشكل فعّال.

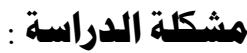

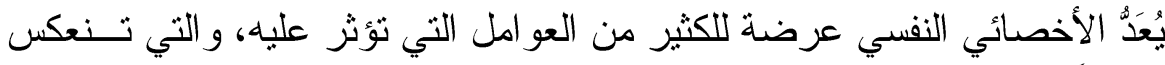

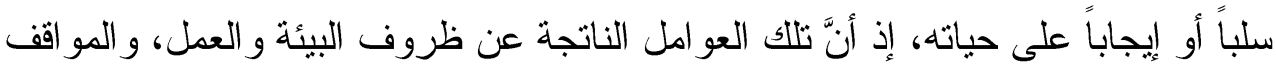
و الأحداث التي تثعلق بوظيفته المتمثلة بالتعامل مع مشكلات الطلاب النفسية و الثخصــية

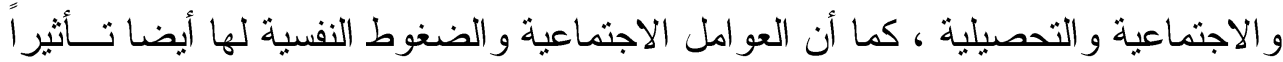
و اضحاً على حياة الأخصائي النفسي، مما يستلزم وجود الصلابة العابة النفسية لديهم.

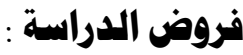
l - هل توجد فروق بين منوسطي درجات الذكور و الإناث من الإخصائيين النفسيين

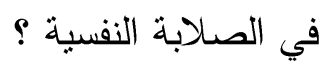
أهداف الدراسة في الهئ. يمكن تحديد أهداف الدر اسة في محاولة التعرف على : ا. الفرق بين الأخصائيات و الأخصائيين النفسيين في الصلابة النية النفسية أهمية الدراسة : الفرق بين

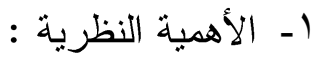
أ- تتتاول هذه الدر اسة فئة من الأخصائيين النفسيين في سلطنة عمان وتحتاج إلى الكثير

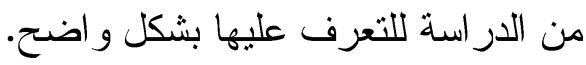

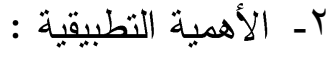

أ- يمكن أن تُهم هذه الدراسة مستقبلاً في وضع تصور لبر امج إرشادية لمواجهة

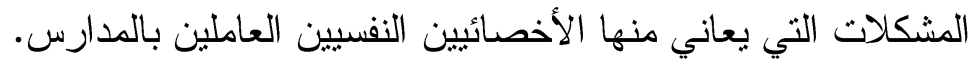

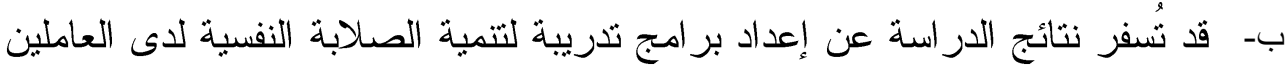

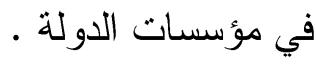


Psychological hardiness الصلابة النفسية

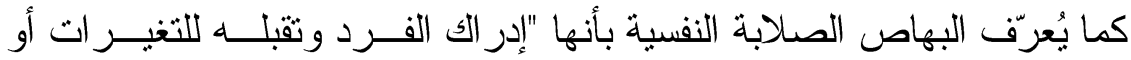

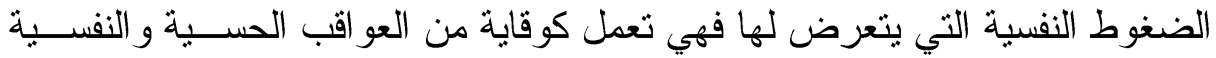

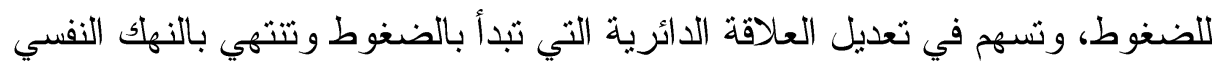

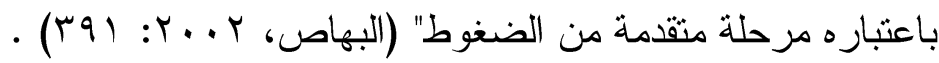

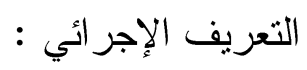

هو الدرجة الكلية الثي يحصل عليها أفر اد عينة الدراسة على مقياس الصلابة النفسية المستخدم في الدر اسة.

r- الإخصائي النفسي الفي في

هو الذي يتخرج من أحد الأقسام الجامعية المختلفة في مجال التشخيص و العلاج النفسي، ويختص بالقياس النفسي وإجر اء الاختبار ات النفسية ودر اسة سلوك العميل

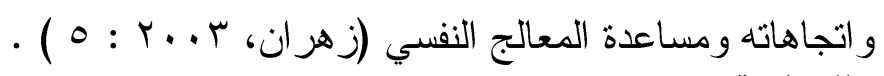

هدود الدراسة :

تتحدد الدر اسة الحالية بالحدود الآثية :

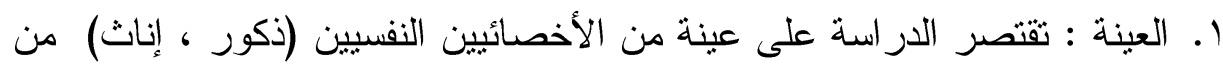

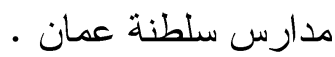
r. الأدو ات : تتحدد الدر اسة الحالية بالأدو ات النفسية المستخدمة فيها وهي ( مقياس

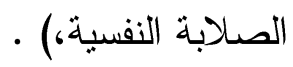
r. المتغير ات: تتحدد الدر اسة الحالية بمتغير ات الصلابة النفسية .

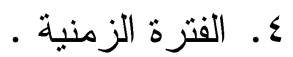

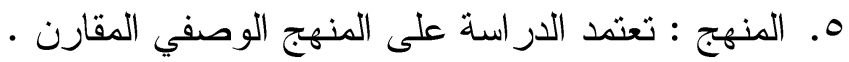

تُعَدُ الصلابة النفسية مصدر أ من المصادر الشخصية الذاتية لمقاومة الآثار السلبية

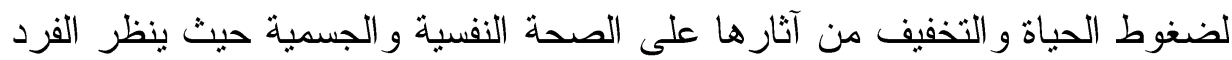
للتغير ات والضغوط التي يتعرض لها على أنها نوع من التحدي وليس ثهايدات، ويظهر الأفراد الذين يتميزون بالصلابة كفاءة في استخدام استراتيجيات التعامل

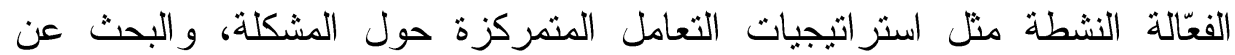

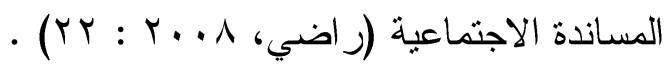
1- أبعاد الصلابة النفسية. 
و الصلابة النفسية تتكون من ثلاثة أبعاد وهي:(الالتز ام، التحكم، التحدي) و أثنار

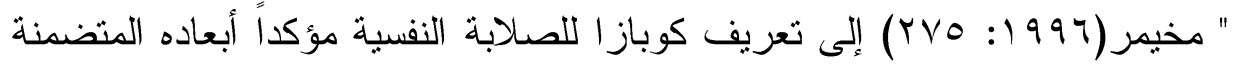

أ- الالتز ام Commitment

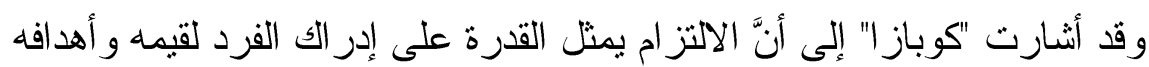

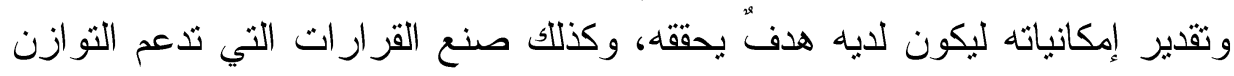

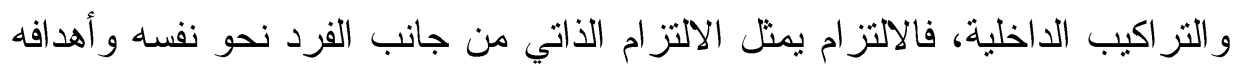

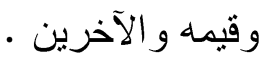

وقد أوضح هاريز Harris أن الالتز ام بمثل "رؤية الفرد أن نشاطات ثلك الحياة

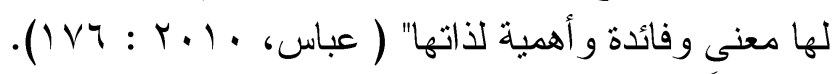

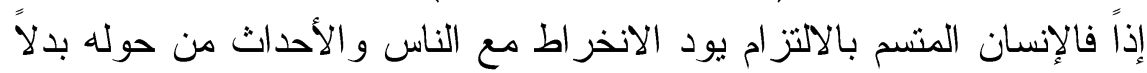
من أن يكون سلبياً ويبدو له هذا الطريث الحصول على الإنى المعنى و التجربة المثيرة،

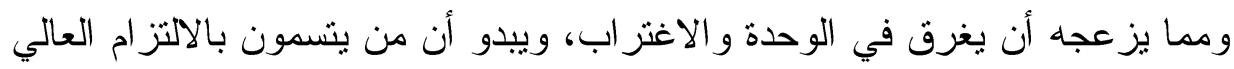

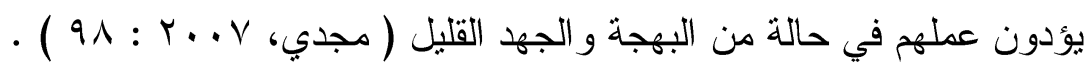

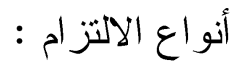

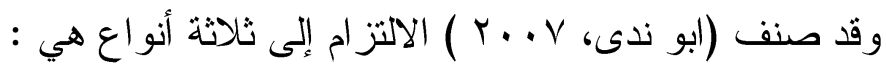

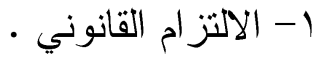

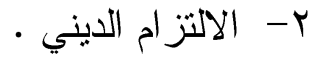

$$
\begin{aligned}
& \text { ب- الالتز ام الأخلاقي الاني . ب- } \\
& \text { ب- التحكم Control : }
\end{aligned}
$$

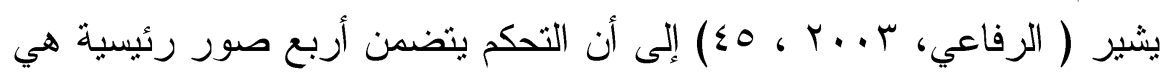

1- القدرة على اتخاذ القرارات و الاختبار بين بدائل متعددة.

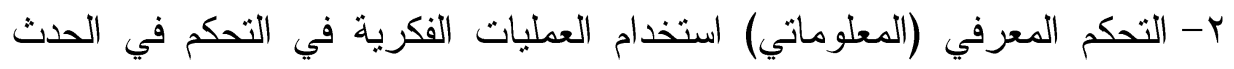
الضاغط. ب- التحكم السلوكي: وهو القدرة على المواجهة الفعّالة على التعامل مع الموقف بصورة علنية، بمعنى تحكم الثخص في أثر الحدث الضاغط من خلال القيام ببعض السلوكيات لتعديله أو تغييره. 
ع التحكم الاسترجاعي: ويرتبط التحكم الاسترجاعي بمعثقدات الفرد السابقة عن . الموقف وطبيعته .

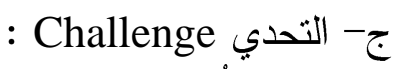
تُعَرِفهُ "كوباز ا" بأنه: " اعتقاد الفرد بأن التغيير المتجدد في أحداث الحياة، هو أمر" طبيعي بل حتمي" لابد منه لارتقائه، أكثر من كونه تهديداً لأمنه و ثقته بنفسه

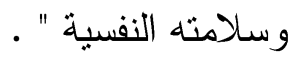

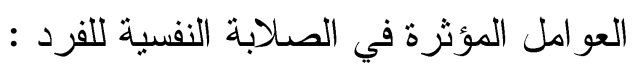

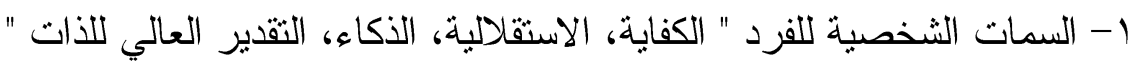

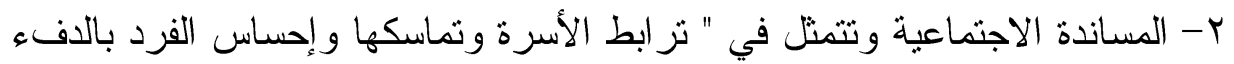

أصبح من المهم دخول خدمات الإرشاد النفسي إلى مؤسساتتا التعليمية، بل وفي كل مؤسسات المجتمع، وهذه قضية تربوية نفسية مجتمعية، تستحق الاهنمام

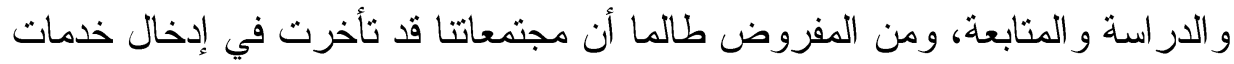

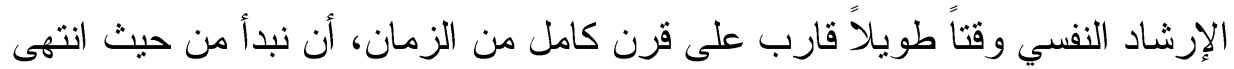

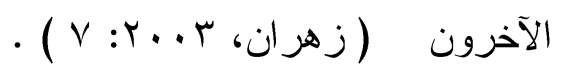

ولقد أصبحت الحاجة إلى المرشد (الإخصائي) النفسي ملحة و ضرو ضرورية في

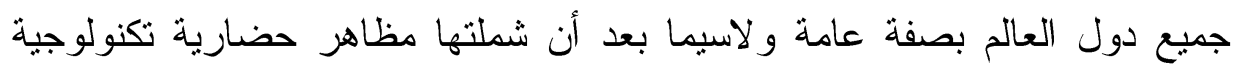

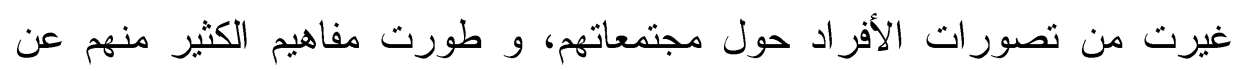

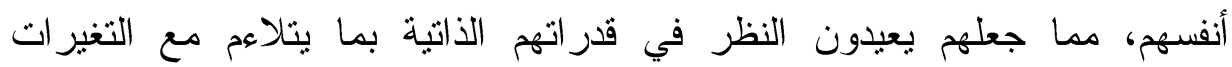

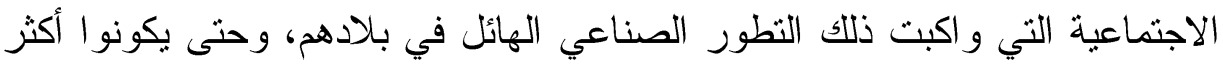

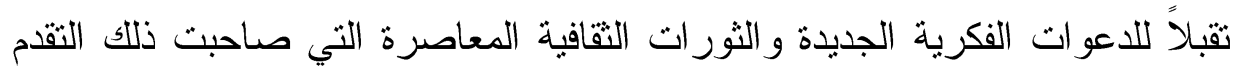

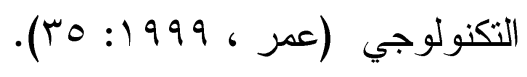

الار اسات السابقة : الدوبة

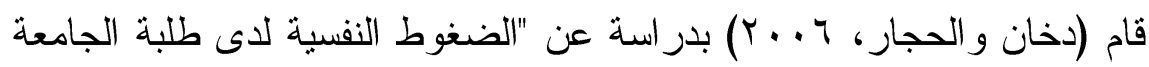

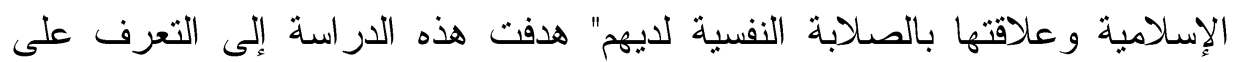

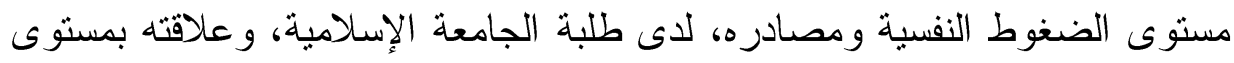

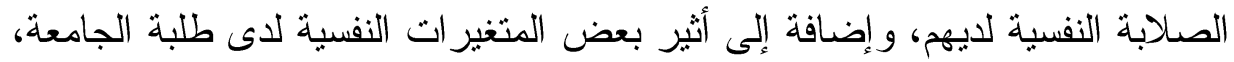
و الصلابة النفسية لديهم، وقد استخدام الباحثان المنهج الوصفي التحليلي، وبلغت عينة 
الدراسة إه طالباً وطالبة. واستخدم الباحثان استبانتين، الأولى لقياس الضغوط

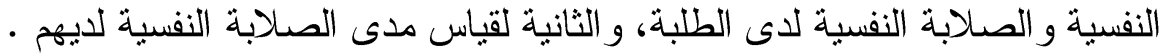

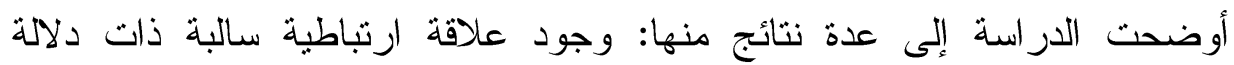

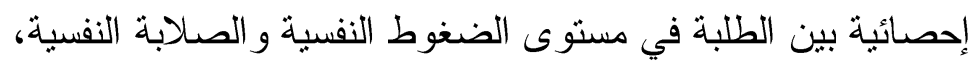

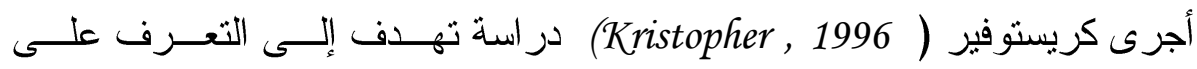

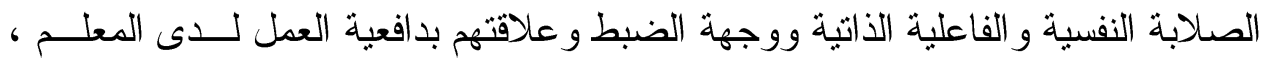

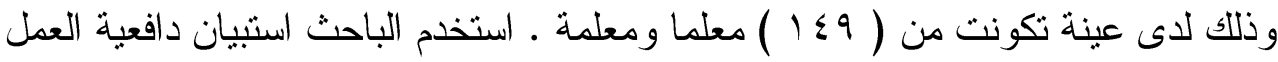

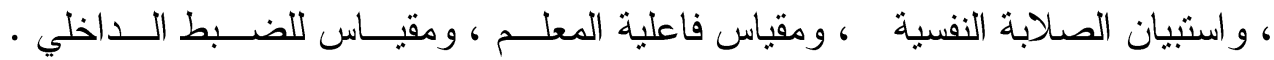

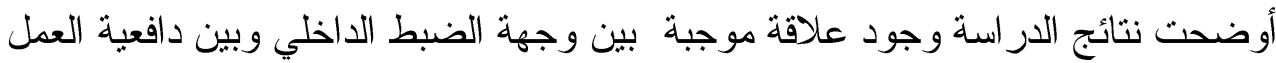

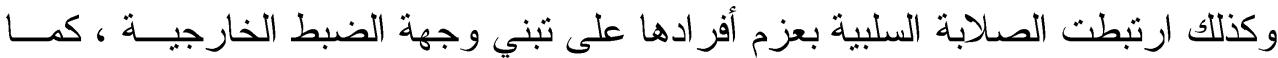

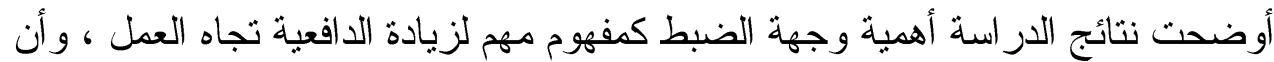

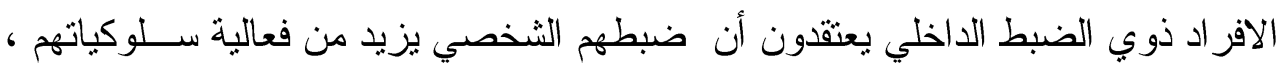

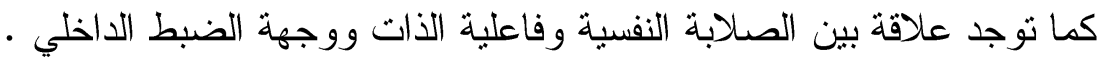

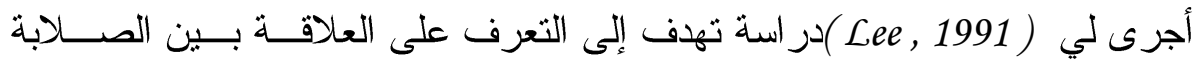

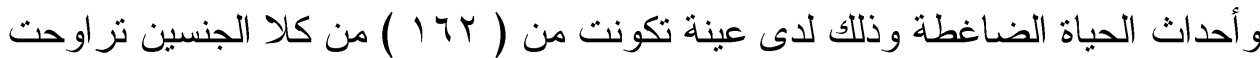

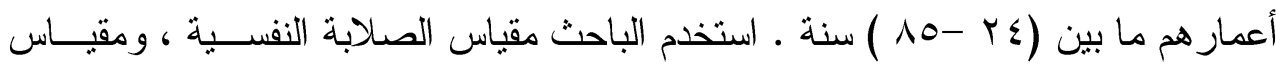

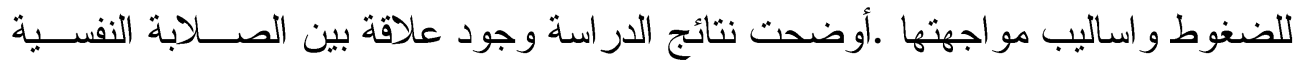

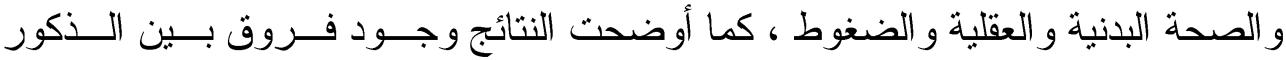

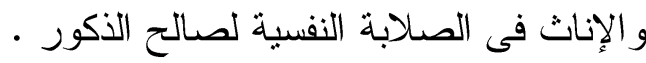

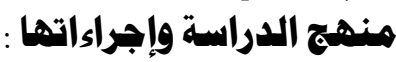
- المنهج المُتبع في الار استة منهج هذه الدراسة هو المنهج الوصفي المقارن ، حيث يثم التعرف على الفروق

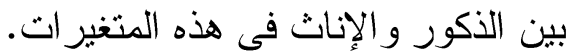

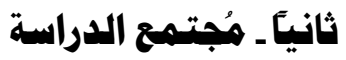

يتكون مُجتمع الدر اسة من جميع الإخصائيين النفسيين في سلطنة عمان و البالغ

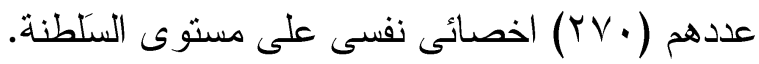

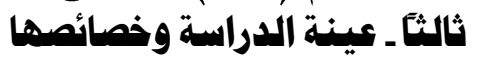

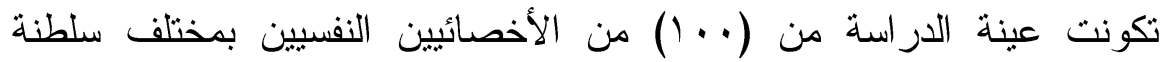

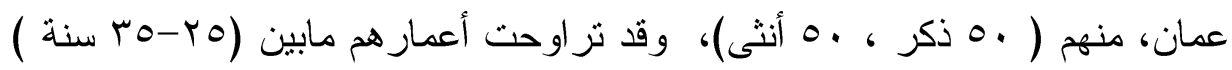

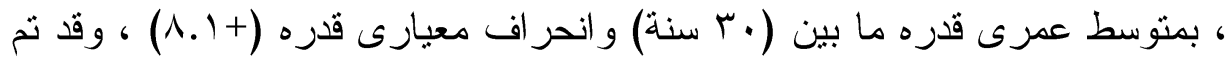


اختيارهم بطريقة عشو ائية من مختلف مدارس سلطنة عمان ، ويوضح جدول (1 )

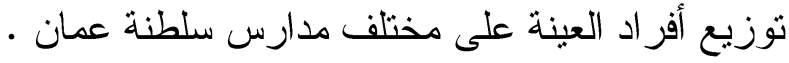

جدول ( ) ثوزيع أفر اد العينة على مختلف مدارس مُحافظات سلطنة عمان .

\begin{tabular}{|c|c|c|c|}
\hline \multicolumn{2}{|c|}{ النوع } & \multirow{2}{*}{ عدد المدارس } & \multirow[t]{2}{*}{ المحافظة } \\
\hline إناث & ذكور & & \\
\hline 7 & 7 & ir & محافظة مسقط \\
\hline 0 & 0 & 1 . & محافظة الباطن شمال \\
\hline$r$ & 0 & V & محافظة جنوب الباطنة \\
\hline$\varepsilon$ & 7 & 1. & محافظة الداخلية \\
\hline 0 & 1. & 10 & محافظة الشرقية جنوب \\
\hline 0 & 0 & 1 . & محافظة الشرقية شمال \\
\hline 0 & $r$ & V & محافظة البريمى \\
\hline r & $r$ & 7 & محافظة الظاهرة \\
\hline 7 & $\varepsilon$ & 1. & محافظة ظفار \\
\hline 0 & $r$ & v & محافظة الوسطى \\
\hline$\varepsilon$ & r & 7 & محافظة مسندم \\
\hline 0. & 0. & \multirow{2}{*}{\multicolumn{2}{|c|}{ المجموع }} \\
\hline & & & \\
\hline
\end{tabular}




\section{رابهَ ـ إجراءات الدراسة الميدانية

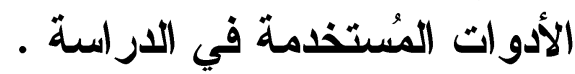

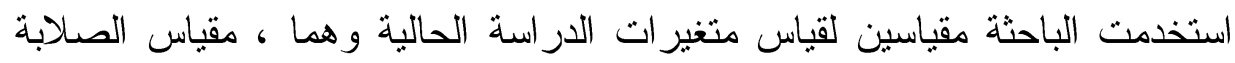

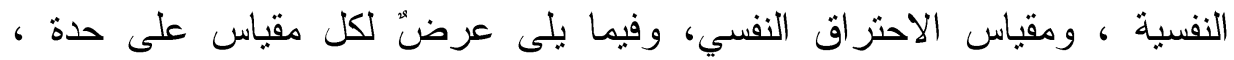
و الخصائص السيكومثرية له :

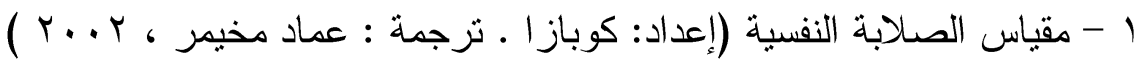
أ - وصف مقياس الصلابة النفسية

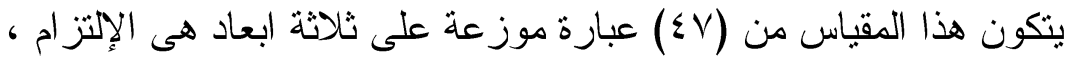

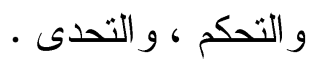

ب - الخصائص السيكومثرية لمقياس الصلابة النفسية :

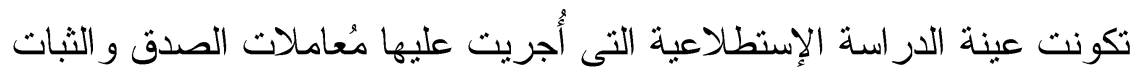

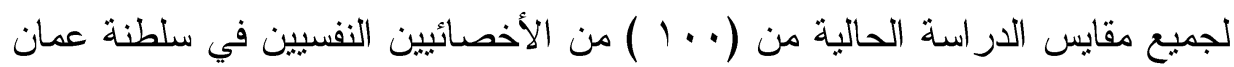

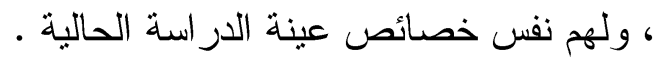

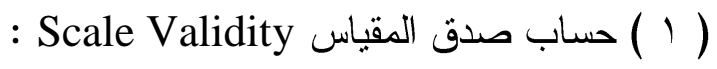
أجرى عماد مخيمر ، r . . . معاملات صدق وثبات لمقياس الصلابة النفسية وتر اوحت ما بين معاملات متوسطة ومرتفعة ، هذا ولم تكتف الباحثة بهذه المعاملات وقامت بالتحقق من صدق وثبات المقياس فى الدر اسة الحالية كما يلى دئى

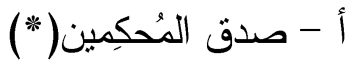
عُرض المقياس على مجموعة من السادة المُحكمِين المتخصصين في علم النفس

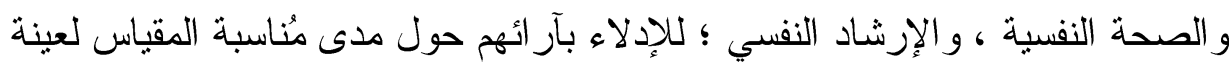

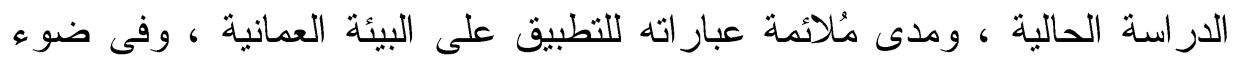

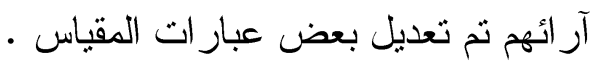

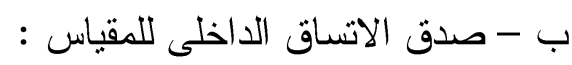

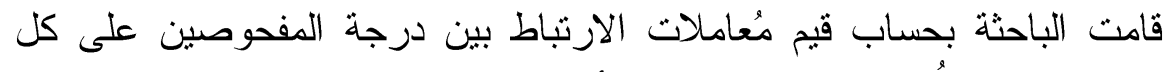

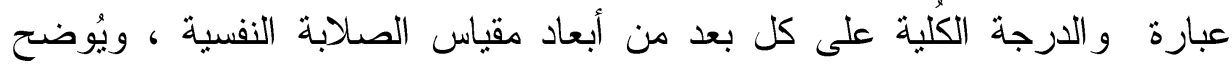

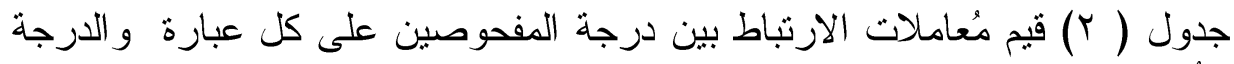

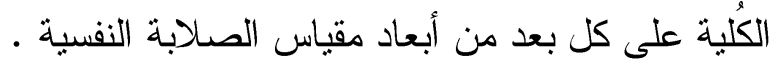

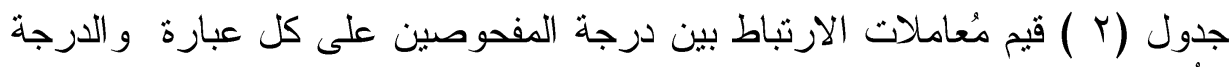

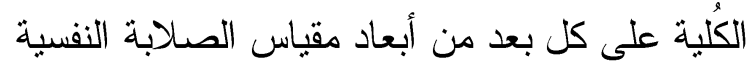


جدول ( r) قيم مُعاملات الارتباط بين درجة المفحوصين على كل عبارة و والدرجة الكُلية على كل بعد من أبعاد مقياس الصلابة النفسية

\begin{tabular}{|c|c|c|c|c|c|c|c|}
\hline قيم مُعامل الارتباط & p & قيم مُعامل الارتباط & r & قيم مُعامل الارتباط & م & قيم مُعامل & r \\
\hline$* * \ldots 1$ & $r V$ & $* * .01$ & rr & $* *$. & $\varepsilon$ & \multicolumn{2}{|c|}{ الإلتزام } \\
\hline. .00 & $\mu$ & $* * .00$ & po & $\ldots 1$ & $\varepsilon r$ & $* * . \leqslant \mu$ & 1 \\
\hline$* * . \leqslant r$ & r & $* * .07$ & $\mu \wedge$ & 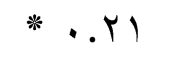 & $\varepsilon q$ & * $\ldots \varepsilon$. & $\varepsilon$ \\
\hline$* * . \leqslant 0$ & mq & ...r & $\{1$ & \multicolumn{2}{|c|}{ التحكم } &..$r$ & $v$ \\
\hline..$r$ & $r q$ & $* * .0$ & $\varepsilon \varepsilon$ & $\ldots r$ & $r$ & **.. I I & 1. \\
\hline$* * \quad . \leqslant 1$ & $\varepsilon r$ & \multicolumn{2}{|c|}{ التحدي } & $* * \varepsilon$ & 0 & $* * . \leqslant 0$ & ir \\
\hline$\cdot . r$ & $\varepsilon 0$ & $* * \ldots$ & $r$ & $* * . \leqslant r$ & $\wedge$ & $* * \quad . \leqslant 0$ & 17 \\
\hline$* * .01$ & $\varepsilon V$ & $* * \ldots \varepsilon$ & 7 & $* * .01$ & 11 & $* * .01$ & 19 \\
\hline & & $* * . . \leqslant \wedge$ & 9 & $* * . \leqslant 0$ & $1 \varepsilon$ & $* * . . \leqslant 7$ & YY \\
\hline & & $* * .0$ & Ir &. .0 & IV & $\cdot \ldots \varepsilon$ & ro \\
\hline & & $\cdot . \varepsilon$ & 10 & $* * .07$ & $r \cdot$ & $* * .0 r$ & $r \wedge$ \\
\hline & & $* * . . \leqslant 9$ & 11 & $* * .0 \wedge$ & $r r$ & $* * \ldots \leqslant \vee$ & ו \\
\hline & & $* * \ldots \Lambda$ & YI & $* *$ * . . & Y & $* * \ldots$ & $r \varepsilon$ \\
\hline & & **.. & $r \leq$ & $* * \quad . \leq \nearrow$ & rq &. .99 & rv \\
\hline & & 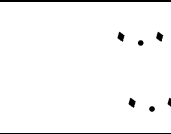 & & *** دالة عند عند & & & \\
\hline
\end{tabular}

يتضح من جدول (r ) ما يلي:

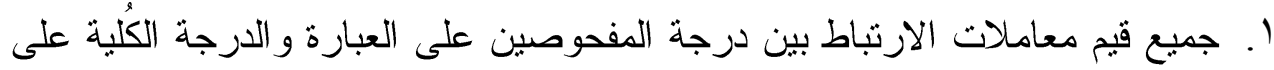

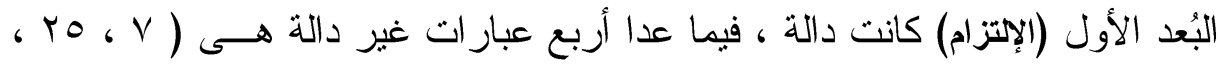

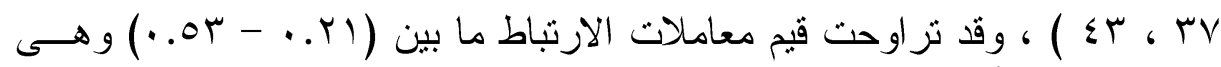

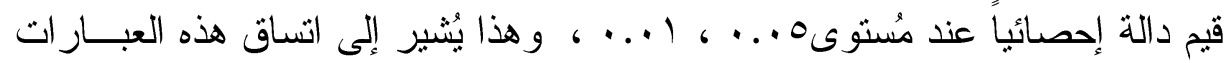

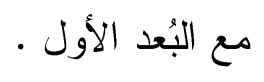

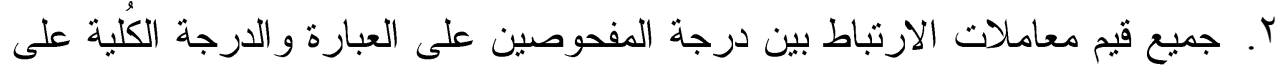

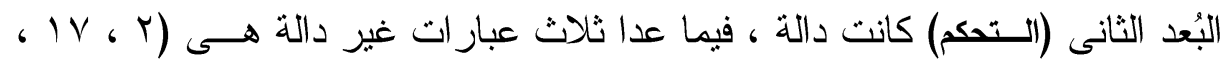




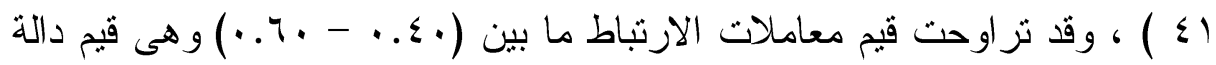

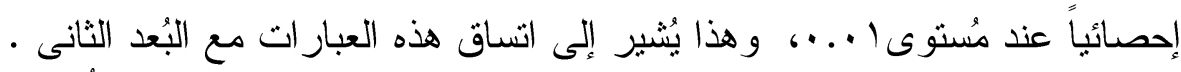

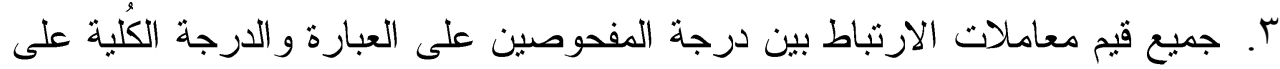

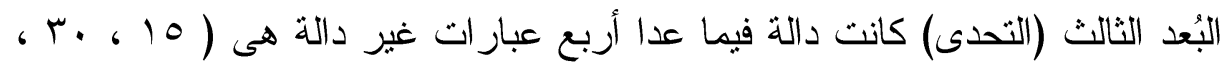

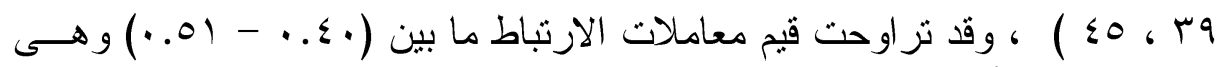

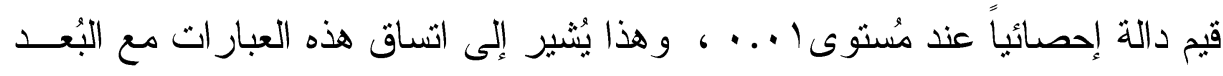
الثالث .

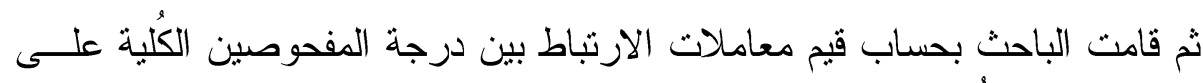

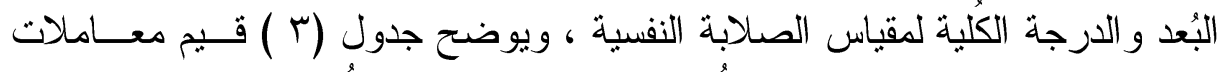

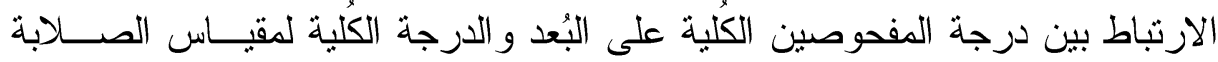
النفسية. جدول ( r) قيم معاملات الارتباط بين درجة المفحوصين الكُلية على البُعد والارجة الكُلية لمقياس الصلابة النفسية

\begin{tabular}{|c|c|c|}
\hline قيم معاملات الارتباط & الأبعاد & م \\
\hline$* * . \wedge 7$ & الإلتز ام & 1 \\
\hline$* * . \wedge$. & التحكم & $r$ \\
\hline$* * .10$ & التحدى & $r$ \\
\hline
\end{tabular}

يتضح من جدول (r ) أنَّ : جميع قيم معاملات الارنباط بين درجــة المفحوصـينين

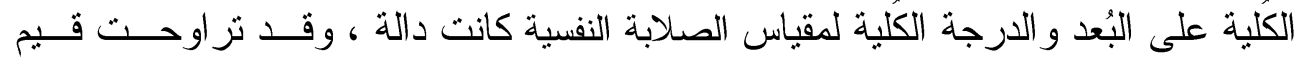

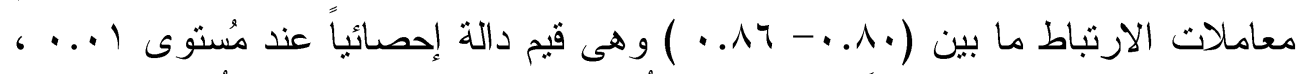

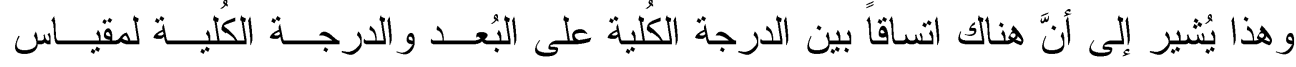
الصدابة النفسية. (ب) حساب ثبات درجات مقياس الصلابة النفسية فى الاراسة الحالية:

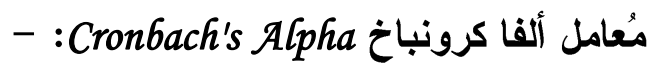

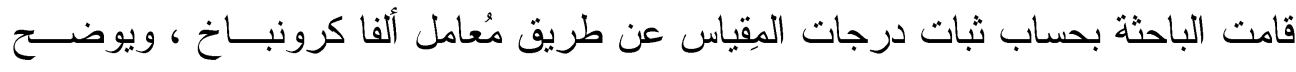

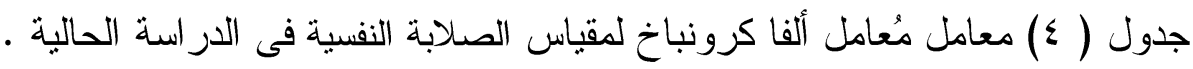


جدول (ء ) مُعاملات ثبات درجات مقياس الصلابة النفسية باستخام مُعامل ألفا كرونباخ

\begin{tabular}{|c|c|}
\hline ألفا كرونباخ & المقياس \\
\hline$* * \ldots$ & الارجة الكلية لمقياس الصلابة النفسية \\
\hline
\end{tabular}

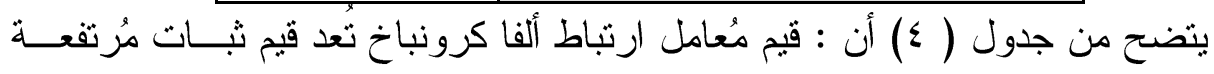

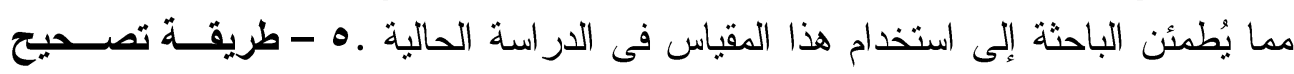

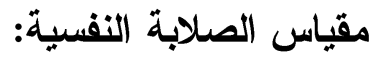

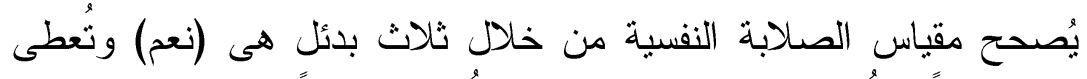

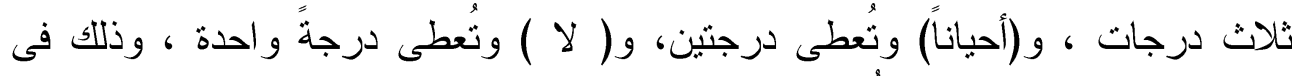
العبار ات موجبة الاتجاه ، وتثتير الدرجة المرتفعة إلى زيادة إدرات الك المستجيب لصلابته النفسية.

\section{4 - وصف مقياس الصلابة النفسية فى صورته النهائية (") :}

يتكون المقياس في صورته النهائية من (דبr) عبارة ، لقياس ثلاثة أبعاد

1. الالتز ام : يشير إلى إحساس الأفر اد بروح تحمل المسؤولية نحو الآخرين و الأحداث في

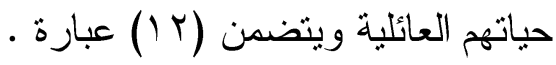

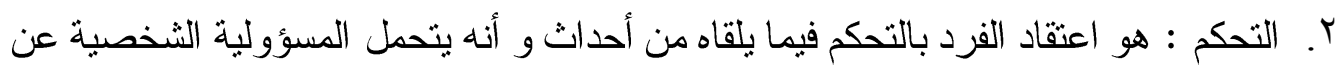

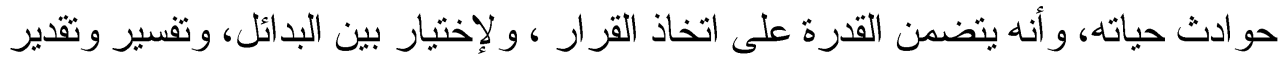

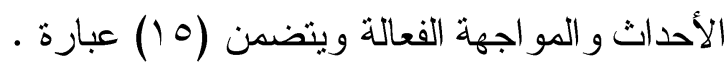

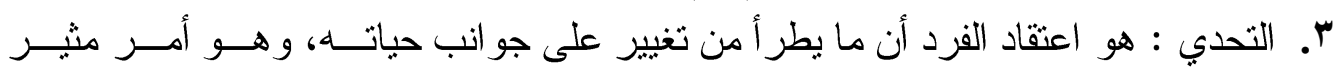

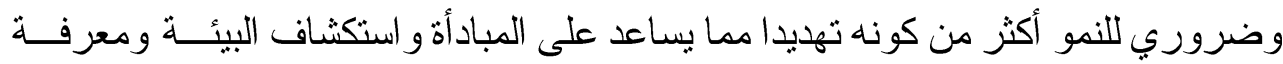

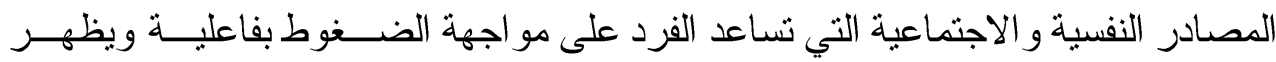

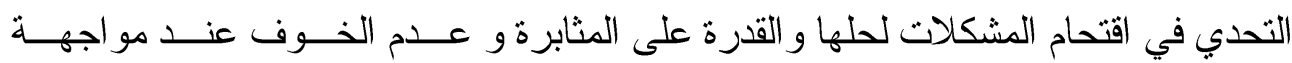

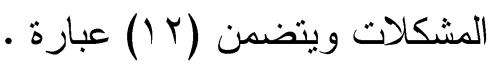
؛ ك. نتائج الدر اسة وتفسير ها: 
توجد فروق ذات دلالة احصائية بين متوسطي درجات الــذكور و الإنــاث مــن

الأخصائيين النفسيين في الصلابة النفسية.

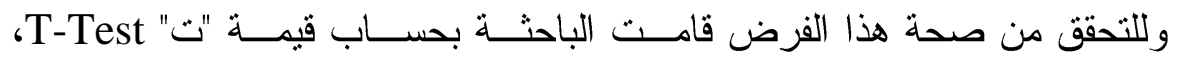
ويوضح جدول(0) دلالة الفروق بين متوسطي درجات الذكور و الإناث من الأخصـائيين النفسيين في الصلابة النفسية.

جدول ( •) دلالة الفروق بين متوسطى درجات الأكور والإناث من الأخصائيين النفسيين في الصلابة النفسية

\begin{tabular}{|c|c|c|c|c|}
\hline قيمة "ت" & الانحر اف المعيارى & المتوسط الحسابى & 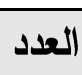 & النوع \\
\hline \multirow{2}{*}{$* * 0.71$} & V.r & $\vee \wedge .0$ & 0 . & الذكور \\
\hline & T.ร & VI.Y & o. & الإناث \\
\hline
\end{tabular}

يتضح من جدول (0) أن هناك فروقاً ذات دلالة احصائية بين متوسطى درجـات

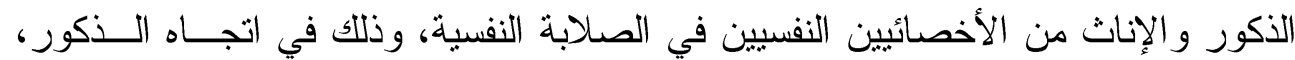
وتشير هذه النتيجة إلى تحقق صحة الفرض. لاحقاتين 


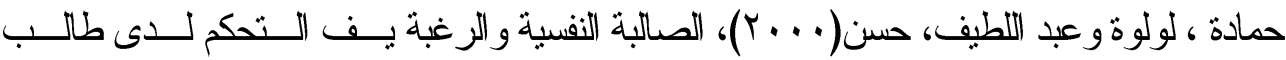

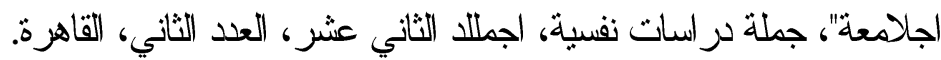

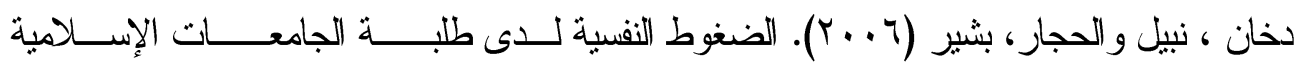

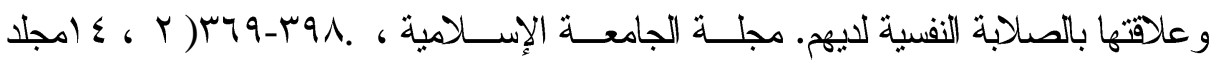

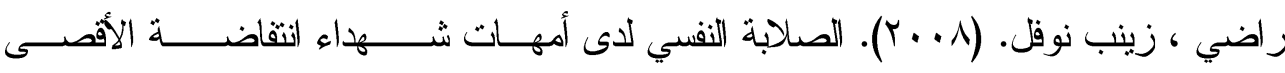
و علاقتها ببعض المتغيرات ، رسالة ماجستير ، قسم علم الــفس ، كلية التزبية ، الجامعة الإسلامية غزة:

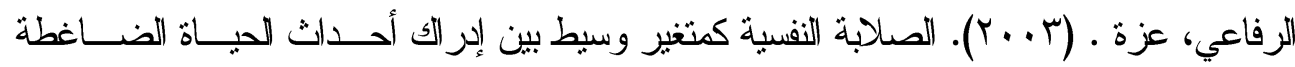

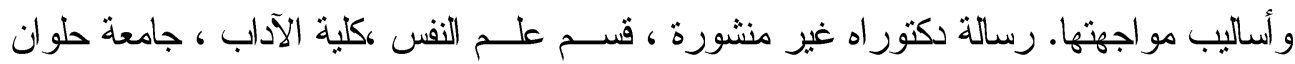
: - ماهرة.

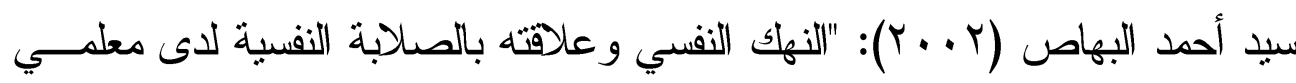
ومعلمات التزبية الخاصة"، مجلة كلية التزبية، جامعة طنطا، العدد الواحد و الثلاثون،

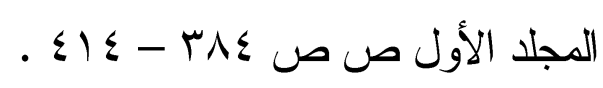

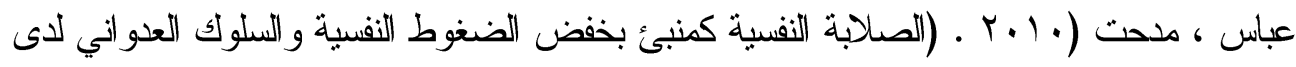

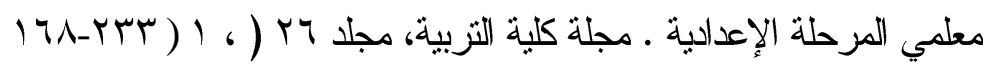

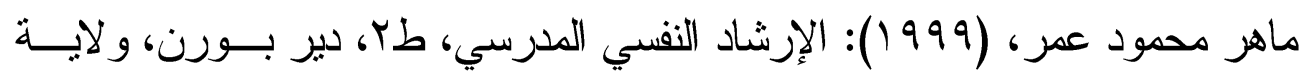
ميتشيجان، الو لايات المتحدة الأمريكية.

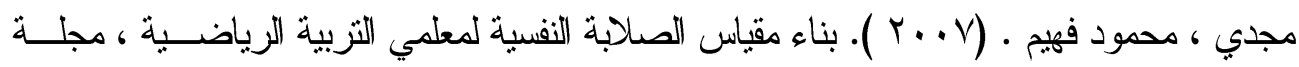

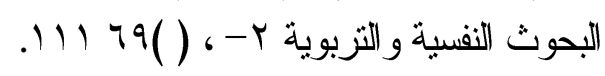

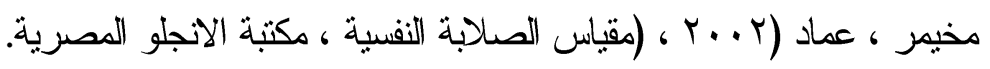

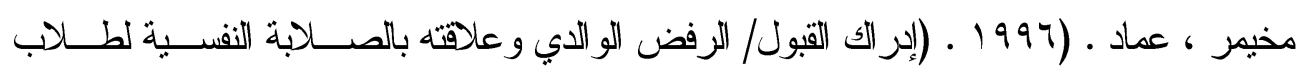

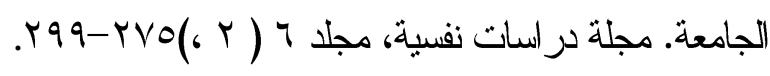

المراجع الانجليزية : kristopherss , A.(1996) .the pleasuvers of psychology icalhavdiness: new American library,newyouk.

Lee, J.(1991). relationship of hardiness and current life events to perceived health in rural adults, research in nursing and health, vol.14,No .(5),pp.351359. 


\section{Abstract}

This study aims to identify the mental toughness among a sample of psychologists in Oman

The study sample consisted of 100 psychiatrists from various areas in the Sultanate of Oman, 50 males and 50 females, aged between 25 and 35 , with an average age of 30 years, and a standard deviation $\left(+\_8,1\right)$. The researcher used Psychological toughness scale (prepared by : Kobaz). The results of the study There are statistical differences between the mean scores of male and female psychiatrists in psychological toughness. And in the male direction, and mention this result to check the health of imposition. Researcher results of the study have been interpreted in the light of the theoretical framework and previous studies have emerged researcher proposed some recommendations and research. 